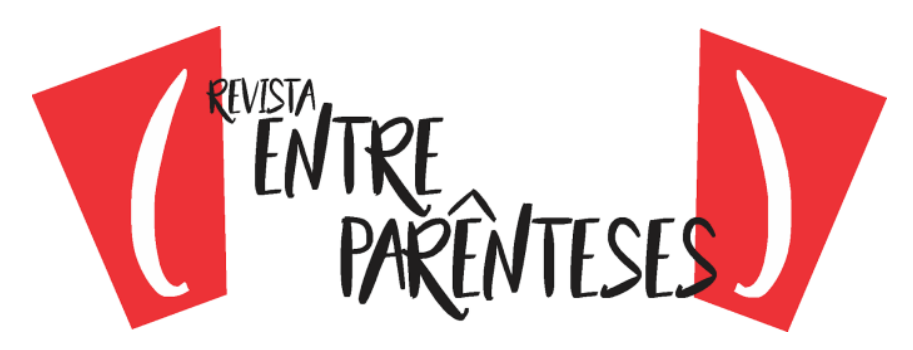

\title{
CUENTOS INFANTILES CLÁSICOS EN VERSIONES POÉTICAS DE GABRIELA MISTRAL: UNA LECTURA INTERPRETATIVA
}

\author{
https://doi.org/ 10.32988/rep.v1n9.1170 \\ Manuel Peña Muñoz ${ }^{1}$ \\ Universidades Andrés Bello y Alberto Hurtado \\ (mapemu@vtr.net)
}

\begin{abstract}
Resumen: En el año 2012 se editaron por primera vez en Chile cuatro cuentos en verso de la escritora chilena Gabriela Mistral (1889-1957), Premio Nobel de Literatura en 1945, inspirados en los cuentos clásicos europeos: "Caperucita Roja", "La Bella Durmiente del Bosque", "La Cenicienta" y "Blanca Nieve en la casa de los enanos". Se trata de un hallazgo literario pues la autora los publicó hace casi cien años en revistas literarias, suplementos culturales y libros de lectura de Chile, México, Costa Rica y Colombia, de modo que estaban dispersos y no se conocían. La editorial Amanuta de Santiago de Chile los publicó en forma de libros independientes. Por esa colección la editorial mereció premios nacionales e internacionales por la cuidada edición de los libros ilustrados por los principales ilustradores chilenos. El presente artículo analiza el origen del proyecto, su significado en la poesía latinoamericana y los simbolismos de cada uno de los cuentos versificados.
\end{abstract}

Palabras-clave: Gabriela Mistral; cuentos infantiles; cuentos en verso.

\section{CONTOS CLÁSSICOS INFANTIS EM VERSÕES POÉTICAS DE GABRIELA MISTRAL: UMA LEITURA INTERPRETATIVA}

Resumo: No ano de 2012 foram editados pela primeira vez no Chile quatro contos em verso da escritora chilena Gabriela Mistral (1889-1957), Prêmio Nobel de Literatura em 1945, inspirados nos contos clássicos europeus: (Chapeuzinho Vermelho, A Bela Adormecida, Cinderela e Branca de Neve e os sete anões. Trata-se de um achado literário, pois a autora os publicou há quase cem anos em revistas literárias, suplementos culturais e livros no Chile, México, Costa Rica e Colômbia, de forma que estavam dispersos e não eram conhecidos. A editora Amanuta de Santiago do Chile os publicou em forma de livros independentes. Por essa coleção a editora recebeu prêmios nacionais e internacionais, graças à cuidadosa edição dos livros, ilustrados pelos principais ilustradores chilenos. O presente artigo analisa a origem do projeto, seu significado na poesia latino-americana e os simbolismos de cada um dos contos versificados.

Palavras-chave: Gabriela Mistral; contos infantis; contos em verso.

1 Escritor, investigador literario, profesor de Castellano, especialista en literatura Infantil y Juvenil, conferenciante, articulista, profesor universitario y autor de numerosos libros de crítica literaria, memorias, ensayos y libros de narrativa y poesía infantil de tradición oral. Autor de las novelas El niño del pasaje (1989) (Editorial Andrés Bello) y Mágico sur (1997) Premio Gran Angular de Novela, Madrid, (Ediciones SM). Sus libros de crónicas más destacados son Ayer soñé con Valparaíso (1999), Chile, Memorial de la Tierra Larga (2002) y Europa en la maleta (2012) en RIL Editores. Ha escrito Historia de la Literatura Infantil en América Latina. Fundación SM Madrid. (2009) e Historia de la Literatura Infantil Chilena. Editorial Andrés Bello. (2009), entre otros. Se ha destacado como director de Seminarios de Literatura Infantil y Juvenil en Chile y conferenciante de temas literarios en España y diversos países latinoamericanos, entre ellos Colombia, Costa Rica, Argentina, Bolivia y Ecuador. En Brasil ha dictado conferencias de literatura infantil latinoamericana en Campinas.

Revista (Entre Parênteses)

Número 9, Volume 1, 2020 - ISSN 2238-4502 


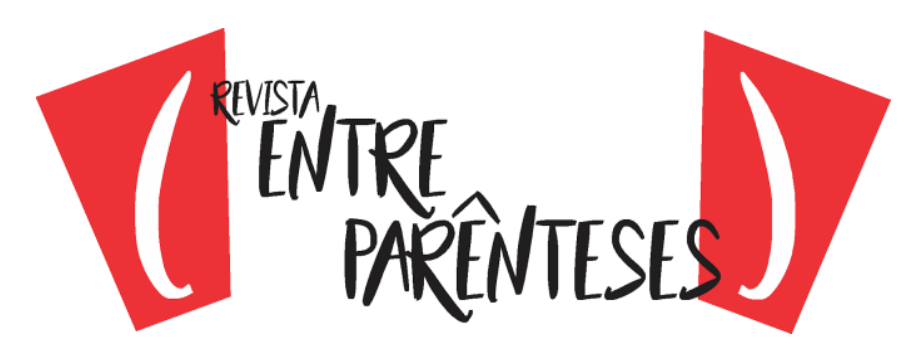

\title{
CLASSIC CHILDREN'S STORIES IN POETIC VERSIONS FROM GABRIELA MISTRAL: AN INTERPRETATIVE READING
}

\begin{abstract}
In 2012, four short stories in verse by Chilean writer Gabriela Mistral (1889-1957), Nobel Prize for Literature in 1945, were published for the first time in Chile, inspired by the classic European tales: (Little Red Riding Hood, Sleeping Beauty, Cinderella and White de Neve and the seven dwarfs. This is a literary finding since the author published them almost a hundred years ago in literary magazines, cultural supplements, and reading books in Chile, Mexico, Costa Rica, and Colombia, so they were scattered and did not know each other. The Amanuta publishing house in Santiago de Chile published them in the form of independent books. For this collection, the publisher received national and international awards, thanks to the careful edition of the books, illustrated by the main Chilean illustrators. This article analyzes the origin of the project, its meaning in Latin American poetry and the symbolisms of each of the versified tales.
\end{abstract}

Keywords: Gabriela Mistral; children's stories; tales in verse.

\section{ORIGEN DEL PROYECTO}

El proyecto de la serie de cuatro cuentos en verso de Gabriela Mistral surgió luego de que el autor de este artículo presentara el proyecto a la editorial Amanuta en una reunión en el Centro Cultural de España de Santiago de Chile en el 2011. Las editoras se interesaron en el proyecto pues se trataba de cuentos de Gabriela Mistral desconocidos en Chile por lo tanto estaban en la línea editorial de rescate de textos de literatura infantil chilena y latinoamericana. Los cuentos los recopilé de distintas fuentes. En uno de mis viajes a Vicuña, en el norte de Chile, encontré en un diario amarillento de los años 30'el cuento "Blanca Nieve en la casa de los enanos", sorprendiéndome con este hallazgo pues no lo conocía. Quizás la misma autora envió esa colaboración para aquel diario. Luego vi este mismo poema en el libro Lecturas clásicas para niños (1924) publicado en México durante los años que vivió Gabriela Mistral residió en ese país. En el libro Croquis mexicanos (1979) publicado por la editorial Nascimento, Alfonso Calderón reúne artículos de Gabriela Mistral escritos en México. En uno de ellos cuenta que "Blanca Nieve en la casa de los enanos" la autora lo leyó en la radio en el momento de irse de México en 1924. 




El poema "Caperucita Roja" lo leí en el libro de lectura El lector chileno (1928) de Manuel Guzmán Maturana cuando era niño, en 1957, justo cuando esta serie de libros de lectura desapareció de la circulación. Nunca se me olvidó. Luego lo leí en el libro Ternura y lo vi manuscrito en el archivo digital de la Biblioteca Nacional.

"La Cenicienta" y "La Bella Durmiente" aparecieron en uno de los tres tomos titulados Gabriela Mistral: su obra y poesía en Colombia (2002). La obra fue recopilada por el investigador colombiano Otto Morales Benítez y publicada por el Convenio Andrés Bello. Este destacado investigador que vino a presentar su obra a la Biblioteca Nacional de Santiago, dedicó parte de su vida a pesquisar en forma exhaustiva diarios, revistas y archivos epistolares para recoger escritos mistralianos publicados en Colombia.

Ya tenía los cuatro cuentos de Gabriela Mistral escritos entre 1924 y 1926. Se trataba de unos cuentos en verso que estaban dispersos. Al reunirlos y ofrecerlos a Amanuta, las editoras invitaron a cuatro ilustradores para que los ilustraran y decidieron darlos a conocer por separado en cuatro libros distintos, cada uno de ellos con un comentario crítico de mi autoría. El resultado fue una obra de arte en el mundo de la edición y una manera muy digna de ofrecer unos cuentos que sorprendieron a los lectores cuando aparecieron pues eran desconocidos. Solo "Caperucita Roja" apareció en el libro Ternura en la edición de Espasa, Calpe, Buenos Aires, 1945, pues en la primera edición de 1924 no aparece. Los otros tres cuentos Gabriela Mistral no los incorporó a ninguno de sus libros de modo que su aparición fue una auténtica sorpresa. Al poco tiempo, los libros merecieron importantes premios nacionales e internacionales. La editorial Amanuta publicó estos cuentos casi cien años después de haber sido escritos, lo que constituye un acierto en la línea de rescate editorial.

La hermosa edición de los cuatro libros fue posible gracias al aporte del Fondo Nacional del Fomento del Libro y la Lectura, en tanto que lo equivalente a los 


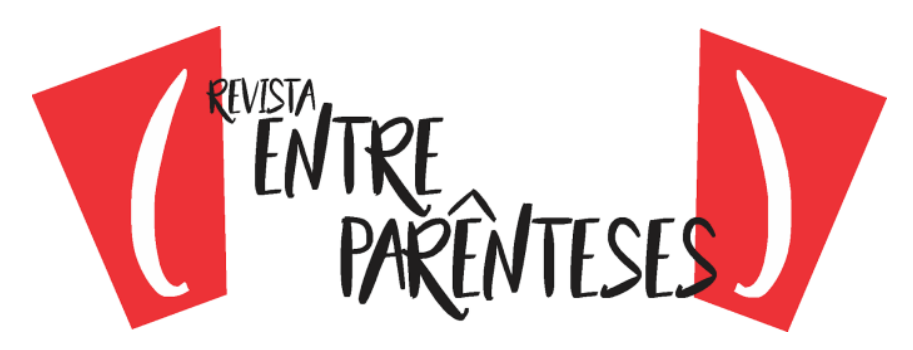

derechos de autoría es entregado a la Orden Franciscana de Chile para los niños de Montegrande y de Chile en conformidad a la voluntad de Gabriela Mistral.

\section{LA AUTORA}

Gran conocedora de la infancia y preocupada de su educación, la maestra rural que fue Lucila Godoy Alcayaga escribió poemas, estampas de viaje, artículos literarios y ensayos sobre la lectura bajo el pseudónimo de Gabriela Mistral (18891957), pseudónimo que toma del escritor italiano Gabriel D’Annuncio y del escritor francés Federico Mistral. Aunque otra versión señala que lo toma del arcángel San Gabriel que veía en la Biblia siendo niña y del viento Mistral que sopla al sur de Francia. Tendría así nombre de arcángel y apellido de viento.

Nacida en Vicuña, Chile, en el valle del Elqui, tierra de vendimiadores y pastores a la que volvió siempre en pensamiento, como se vuelve a la patria de la niñez, Gabriela Mistral escribió páginas notables en las que recreó los cuentos infantiles clásicos transmitidos de generación en generación y la poesía infantil de tradición oral. Gustó de la ronda, el romance, el cuento popular y la canción de cuna. Colaboró con los grandes educadores reformistas de Latinoamérica, principalmente con el poeta, filósofo, educador y Ministro de Instrucción Pública, José Vasconcelos en México, país que la acogió y valoró desde sus inicios y a donde llegó en 1922 desde Chile, con 33 años, permaneciendo en el país hasta 1924. Allí fue feliz descubriendo ciudades, pueblos y paisajes, impregnándose de mexicanidad.

Escribió acerca de los cielos de México y de las artesanías de los indígenas. Observó las plantas, aves, flores y árboles del país, interesándose en el maguey y la palma real: "El indio mexicano ama la palma, la pinta en la mejilla de su cántaro en Guadalajara y la lleva en sí mismo; su cuerpo fino y acendrado tiene algo de ella". ${ }^{2}$ También escribió sobre el clima de Veracruz, "recados" sobre Michoacán,

2 Mistral, Gabriela. Croquis mexicanos. Selección y prólogo de Alfonso Calderón. Editorial Nascimento. Santiago, 1979. Página 67.

Revista (Entre Parênteses)

Número 9, Volume 1, 2020 - ISSN 2238-4502 


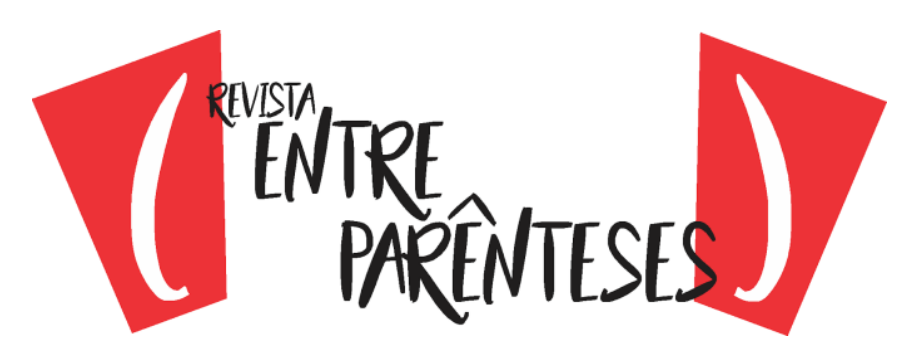

una puerta colonial en la catedral de Puebla, reflexiones sobre las escuelas granjas y artículos sobre la mujer mexicana que reunió en su libro Lecturas para Mujeres (1923) destinado a la educación y la enseñanza del lenguaje, escrito con gran lirismo y espiritualidad. Identificada con el indigenismo, escribió una "Silueta de la india" así como una semblanza de Sor Juana Inés de la Cruz y un comentario crítico sobre la obra de María Enriqueta, autora de libros de lectura, que la revela como una escritora interesada en leer a los autores del país que visita.

Preocupada siempre de la educación a través de la lectura, visitó bibliotecas populares en regiones apartadas de México, promovió los libros infantiles y dictó conferencias sobre el valor formativo de la literatura. Con Palma Guillén escribió Lecturas clásicas para niños (1924) en dos tomos, con prólogo de José Vasconcelos, con el propósito de inculcar desde la infancia el gusto por la lectura de los mejores autores universales. La obra que hoy es una joya bibliográfica, contiene narraciones, mitos, leyendas, cantares de gesta y cuentos de sabor folclórico. En torno a la lectura, escribe:

La faena en favor del libro que corresponde cumplir a maestros y padres es la de despertar la apetencia del libro, pasar de allí al placer mismo y rematar la empresa dejando un simple agrado promovido a pasión. Lo que no se hace pasión en la adolescencia se desmorona hacia la madurez relajada. ${ }^{3}$

Y luego recomienda: "Hacer leer, como se come, todos los días, hasta que la lectura sea, como el mirar, ejercicio natural, pero gozoso siempre". 4

Con una tabla apoyada en sus rodillas, escribe "Los Derechos del Niño" reivindicando su lugar en la sociedad: "El niño debe tener derecho a lo mejor de la tradición, a la flor de la tradición, que en los pueblos occidentales, a mi juicio, es el cristianismo". ${ }^{5}$

\footnotetext{
${ }^{3}$ Mistral, Gabriela. Magisterio y Niño. Pasión de Leer. Selección de prosas y prólogo de Roque Esteban Scarpa. Editorial Andrés Bello. Santiago, 1979. Página 101.

${ }^{4}$ Ídem. Página 101.

5 Ídem. Los derechos del niño. Página 64.

Revista (Entre Parênteses)

Número 9, Volume 1, 2020 - ISSN 2238-4502
} 


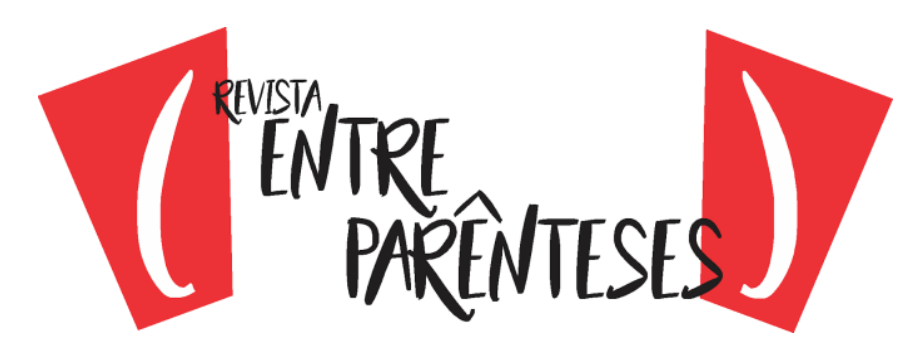

Interesada por la problemática social de la infancia, escribe:

Muchas de las cosas que hemos menester tienen espera. El niño, no. Él está haciendo ahora mismo sus huesos, criando su sangre y ensayando sus sentidos. A él no se le puede responder 'mañana'. Él se llama 'ahora'. ${ }^{6}$

Sus páginas en prosa se prestan muy bien para cultivar en los niños el amor hacia la belleza, la educación de los sentimientos, la naturaleza y el paisaje vernáculo. Para ellos, escribió poesía y cuentos de tono modernista que nos evocan los escritos por Rubén Darío, José Martí y Oscar Wilde. Son cuentos delicados y filosóficos como "Por qué las rosas tienen espinas", "La raíz del rosal" y "Por qué las cañas son huecas", con profundos simbolismos y riqueza de léxico.

Por su poesía lírica, su visión americanista y su preocupación por la infancia en Latinoamérica, mereció el Premio Nobel de Literatura en 1945, después de cuatro años de haber sido interrumpido por causa de la Segunda Guerra Mundial, siendo la primera y única mujer en lengua castellana en recibirlo.

\section{LECTURA Y LITERATURA INFANTIL}

La maternidad, la educación, la mujer, la infancia y el indigenismo, fueron sus temas predilectos, pero fundamentalmente la educación humanista a través del libro, le preocupó siempre:

Pasión de leer, linda calentura que casi alcanza a la del amor, a la de la amistad, a la de los campeonatos. Que los ojos se vayan al papel impreso como el perro a su amo; que el libro, al igual de una cara, llame en la vitrina y haga volverse y plantarse delante en hechizo real; que se haga leer un ímpetu casi carnal; que se sienta el amor propio de haber leído libros mayores de siempre y el bueno de ayer; que la noble industria del libro exista para nosotros por el gasto que hacemos en ella, como existen los tejidos y alimentos, y que el

${ }^{6}$ Ídem. Llamado por el niño. Página 71.

Revista (Entre Parênteses)

Número 9, Volume 1, 2020 - ISSN 2238-4502 


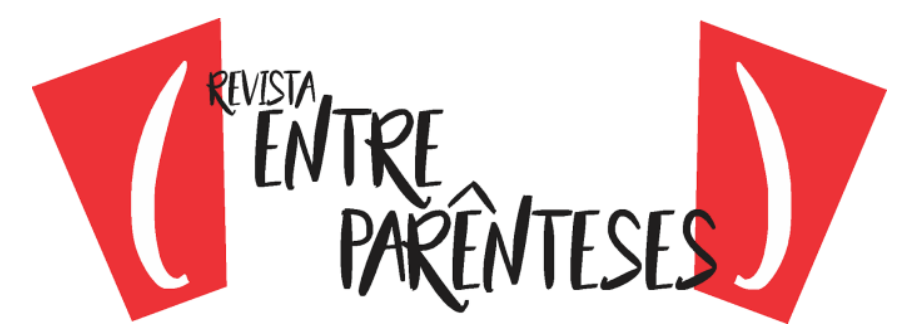

escritor se vuelva criatura presente en la vida de todos, a lo menos tanto como el político o industrial. ${ }^{7}$

En relación a la literatura para niños, la autora creía que debía ser aquella inspirada en el folclore. Según su pensamiento, en los arrullos, adivinanzas, rimas, cuentos de nunca acabar, retahílas, canciones para saltar al cordel, rondas o canciones de corro y romances transmitidos por vía oral, estaba la verdadera cantera capaz de cautivar al niño y guiarlo en la senda de la poesía y del arte. Es entonces cuando escribe: "La primera lectura de los niños sea aquella que se aproxima lo más posible al relato oral, es decir, a los cuentos de viejas y a los sucedidos locales". ${ }^{8}$

En "El Folklore de los Niños" publicado en 1936 en la "Revista de Pedagogía" de Madrid, señala que en estas viejas fórmulas de la lengua oral, estaba la clave de la poesía que debía escribirse para los niños, una poesía que si no se canta, debería ser escrita para ser cantada. En otra ocasión, escribe: "En la poesía popular española, en la provenzal, en la italiana del medioevo, creo haber encontrado el material más genuinamente infantil de rondas que yo conozca". ${ }^{9}$ Consideraba que el propio folclore adulto de esas regiones estaba lleno de piezas válidas para los niños. ¿No fueron cuentos de la tradición oral los que luego se difundieron entre la infancia en versiones recreadas? Gabriela Mistral lo sabe y retoma incluso los cuentos populares de antaño de Charles Perrault transmitidos por vía oral de generación en generación. Allí está "Caperucita Roja", el cuento clásico por excelencia que va a tener ahora una nueva interpretación y otro estilo al compás de su ritmo.

\section{CAPERUCITA ROJA}

\footnotetext{
7 Ídem. Pasión de leer. Página 102.

8 Ídem. Pasión de leer. Página 101.

${ }^{9}$ Mistral, Gabriela. Poesía y prosa. Selección, prólogo, cronología y bibliografía de Jaime Quezada. Biblioteca Ayacucho. Caracas, Venezuela, 1993. Impreso en Chile. Página 21.
} 


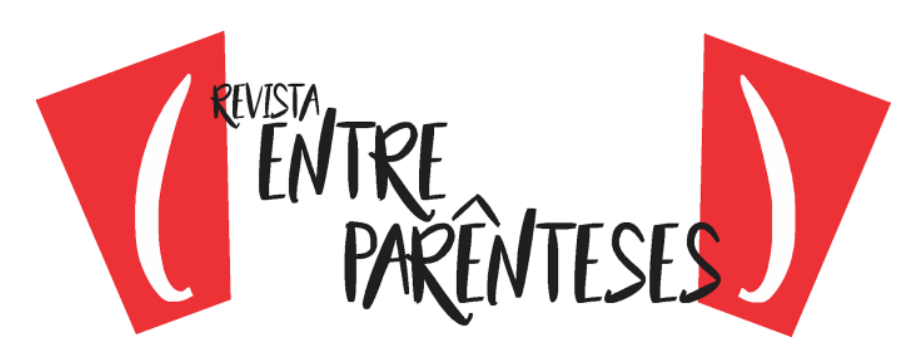

En la versión mistraliana de "Caperucita Roja" vemos a una autora fiel al cuento escrito por Charles Perrault con la intención de moralizar a las jóvenes que asistían a las tertulias de la aristocracia francesa en tiempos del rey Luis XIV. Aunque, en realidad, el cuento era de tradición oral pues circulaba desde tiempos inmemoriales en labios de campesinos, pastores y aldeanas que lavaban en los ríos. Charles Perrault lo recogió de sus criadas y lo recreó por escrito para ese público de doncellas casaderas, advirtiéndoles del peligro que podía acecharles si no estaban prevenidas... Es pues, desde sus inicios, un "cuento de advertencia".

En el siglo XIX el cuento llegó transformado por la tradición oral a Alemania y así lo encontramos en la versión de los hermanos Grimm que suprime la moraleja en verso y agrega un final feliz en la que aparece un personaje nuevo, en este caso, un cazador, o leñador en otras versiones, que salva a la abuela y su nieta del vientre del lobo y le da castigo, llenándole el estómago con piedras y arrojándolo al río o a un pozo. En este caso, los autores alemanes sugieren una moraleja implícita que enseña a los niños a ser obedientes, aspecto que no estaba en la versión original.

Durante el siglo XX comenzaron a escribirse nuevas versiones y a partir de la Segunda Guerra Mundial, se han escrito más de cien variantes, pues cada escritor, como un verdadero lobo, se apropia de esta niña y crea su propio cuento, conservando lo esencial de la historia. Gabriela Mistral también se sintió atraída por el más universal de todos los cuentos. Apegada a las raíces folclóricas, no cede al gusto moralista de la época pues podría haber escogido la versión de los hermanos Grimm, mucho más concesiva y blanda que la de Charles Perrault, sin embargo, prefiere la versión original, más dura, aunque tenga un final trágico. En su versión, la autora escoge el verso alejandrino que gustaba tanto a los poetas modernistas, es decir, de catorce sílabas perfectas: "Caperucita Roja visitará a la abuela", 


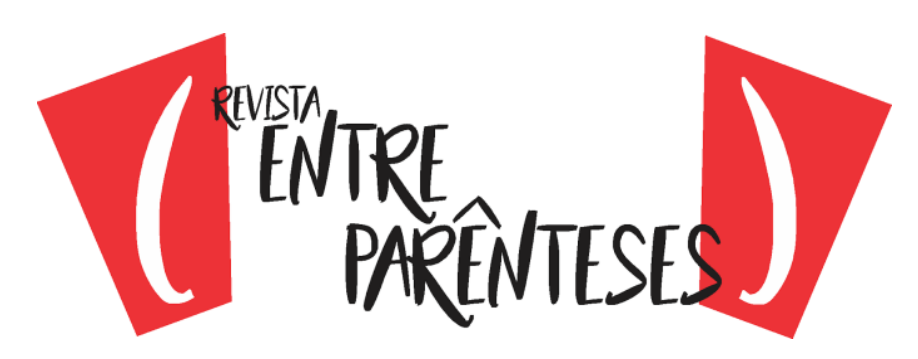

"Caperucita Roja la de los rizos rubios". Atención. Aquí hay un detalle que no aparece en otras versiones, pues ahora sabemos que la niña es rubia en su versión.

Más adelante, utiliza giros arcaicos como "Maese", forma antigua para designar al Maestro, utilizando también la mayúscula tal como acontece en la versión original escrita por Perrault. Así escribirá: "Sale al paso Maese Lobo". También emplea cultismos como la palabra "alcor": "El lobo ha pasado ya el bosque, el molino, el alcor". Aquí nos obliga a ir al diccionario para buscar su rico léxico que complejiza el cuento y lo vuelve misterioso. Así sabemos que "alcor" es un sinónimo de colina o loma pues al otro lado se levanta la casa de la abuelita. Epítetos muy originales enriquecen esta versión. Al lobo lo llama "velludo engañoso", en tanto que Caperucita Roja es descrita con una acertada comparación, ya que es "cándida como los lirios blancos".

Nuevos giros idiomáticos aproximan el cuento a la narración oral: "Ha tres días que no sabe de bocado". Va al hueso de la versión original sin disfrazarla: "Se la comió riendo toda y pausadamente / y se puso enseguida sus ropas de mujer". Del mismo modo, cuando el Lobo dice: "Ven a entibiarme el lecho", la autora escribe en forma audaz para su época: "Caperucita cede al reclamo de amor", ajustándose así al texto de Charles Perrault que escribe: "Caperucita roja se desnudó y fue a meterse en la cama". Gabriela Mistral no escamotea esta escena como ocurre en todas las versiones posteriores, con lo cual se adelanta a todas las interpretaciones psicoanalíticas de Bruno Bettelheim y otros críticos literarios que verán en esta escena una clara connotación sexual, tal como se ha venido interpretando a lo largo de todo el siglo XX.

El cuento ha sido estudiado por psicoanalistas, etnógrafos, semiólogos, antropólogos y educadores que lo interpretan desde distintos ángulos, del mismo modo que la imagen de la niña ha dado pie para que los ilustradores hayan realizado sus propias interpretaciones, a partir de la ilustración clásica fijada por los grabados de Gustave Doré en el siglo XIX. 




Hacia las últimas páginas, la autora se apega a la secuencia clásica de los diálogos: "Abuelita, decidme ¿por qué esos grandes dientes?" / "Corazoncito, para devorarte mejor". El final demoledor, nos deja impactados pues es fiel al final del cuento clásico de Perrault quien escribe: "iSon para comerte! Y diciendo estas palabras, el malvado Lobo se arrojó sobre Caperucita Roja y se la comió". Gabriela Mistral escribirá: "Y ha exprimido como una cereza el corazón".

Las ilustraciones de esta versión poética corresponden a la ilustradora Paloma Valdivia, de reconocida experiencia y prestigio, tanto en Chile como en el extranjero, quien enriquece el texto con unas ilustraciones claras, de colores luminosos y alegres, con una gran dosis de sugerencia expresiva.

\section{BLANCA NIEVE EN LA CASA DE LOS ENANOS}

Como se ve, Gabriela Mistral ha leído a los autores clásicos europeos que recogieron el rico folclore de la infancia. Si lee a Charles Perrault, también lee a los hermanos Grimm y a Hans Christian Andersen que recreó la mitología popular escandinava. Su poema "Piececitos" presenta el tema de la niñez desamparada que está presente en el cuento "La vendedora de cerillas" de Andersen, del mismo modo que cuando escribe: "Una niña que era inválida/ dijo cómo danzo yo"10, está poniendo en relieve a una niña minusválida, tal como los presentaba Andersen en sus cuentos protagonizados por niños lisiados o incluso juguetes, como ese soldadito de plomo al que le falta una pierna.

En el cuento "Blanca Nieve en la casa de los enanos", la autora recrea un fragmento del cuento "Blancanieves" de los hermanos Grimm recogido en el libro Cuentos de la Escuela y el Hogar publicado en Alemania en 1812. De este cuento escoge la escena del encuentro de los siete enanos con la protagonista a la que bautiza Blanca Nieve. De este modo, consigue un efecto poético desde el título que

10 Ídem. Los que no danzan. Página 70.

Revista (Entre Parênteses)

Número 9, Volume 1, 2020 - ISSN 2238-4502 


\section{("ifing}

recrea al separar las palabras y poniendo el sintagma en singular. Además circunscribe el cuento al episodio que vive la niña dentro la casa de los enanos, de carácter más íntimo, y suprimiendo las escenas dramáticas como las tres visitas de la reina disfrazada de bruja, ofreciéndole cintas, peines y una manzana a la joven, tal como aparece en el cuento original. En versiones posteriores estas tres visitas de la reina se han reducido a la final en la que solo le ofrece la manzana envenenada.

Su versión del cuento se apega esta vez al verso octosílabo, es decir, versos de ocho sílabas que van relatando la historia de una manera fluida, lo que muestra su facilidad por la métrica clásica.

El tono empleado es de gran dulzura con figuras literarias asociadas a la maternidad como cuando expresa que la casa de los enanos "pestañea en la sombra como una madre que llama". Las comparaciones tienen también delicadeza. Las puertas de la casa "se abren como dos alas". Las camitas de los enanos "son tan suaves como la nata".

La autora emplea las figuras retóricas de la narración: "La casa sigue tan muda como si ha siglos callara" lo que muestra su interés en conservar el estilo literario del cuento narrado oralmente con un giro arcaico. Muy rica desde el punto de vista literario, es la descripción de la mesa de los enanos donde los saleros se convierten en "siete ampollas de sal cándida". Gabriela Mistral maneja la metáfora de modo natural, lo mismo la hipérbole, ese recurso literario para exagerar, aumentando o disminuyendo la realidad, en este caso, las camitas "son del largo de un jazmín".

La secuencia de las preguntas de los enanos al entrar a la casa, recuerda una similar del cuento popular de origen inglés "Ricitos de Oro" cuando la familia de osos entra a la casa y descubre que ha entrado alguien: "¿Quién se ha sentado en mi silla?" se preguntan el oso y los enanos, respectivamente en ambos cuentos. También en ambos casos, una visitante desconocida que duerme en una de las camas. Son tres, las camas de "Ricitos de Oro" y siete en este cuento. "Hay una niña 




en mi cama" dice sorprendido el osito en "Ricitos de Oro" en tanto que en esta versión, un enano exclamará: "Hay una niña en mi casa" lo que demuestra el conocimiento y la recreación que hace la autora de los cuentos de origen folclórico europeo. Por otro lado, respeta el recurso de las preguntas, tan propio de la narración oral, que confieren ritmo y naturalidad a las escenas.

En este cuento, la autora acentúa la escena de los enanos preguntándose en voz alta quién entró a la casa: “¿Quién dio más luz a mi lámpara?”. Inspirada en la naturaleza, la autora emplea comparaciones hiperbólicas con las flores y los árboles. Si las camas de los enanos eran "del largo de un jazmín", la de Blanca Nieve por oposición será "grande como un haya". Y los enanos la llamarán con nombres que provienen de la naturaleza: "olor de salvia mojada", "cuesta de almendros blancos"...

El cuento versificado posee un rico vocabulario. Blanca Nieve "despierta entre la algarada". Aquí ha empleado un arabismo para designar el ruido de los enanos saltando de alegría junto a la niña que duerme, tal como duerme la Bella Durmiente en el cuento de Charles Perrault. Como se ve, las escenas clásicas transitan de un cuento a otro.

Hacia el final, viene el conjuro de los enanos espantando las imágenes que pueda tener la niña. No quieren despertarla de su sueño profundo. La dejarán dormir "hasta que cante el gallo" y no querrán que sueñe con "la catarina giganta". ¿Qué quiere decir? Como la autora escribe esta versión estando en México, se ha impregnado del vocabulario local, con lo cual sus textos se impregnan de americanismos. Si los enanos velan su sueño es porque no quieren que sueñe con "la catarina giganta" es decir no quieren que ni en sueños vea a la Muerte pues en México la llaman Catarina o Catrina. También a nuestra "chinita" de caparazón naranja y puntitos negros, la llaman "catarina" en México, "mariquita" en Colombia y "vaquita de san Antón" en Argentina. La autora introduce en esta ocasión un mexicanismo con lo cual se apropia del personaje europeo y lo americaniza, 




mencionando además a un lagarto que conocerá en el trópico, lo que refleja su interés en nuestros animales e insectos americanos. Por tanto, los enanos no quieren que su "bella durmiente" tenga pesadillas con un "lagarto volador" o una "catarina giganta". Finalmente, los enanos velan el sueño de Blanca Nieve. La autora los llamará "los duendes de los metales" en una hermosa metáfora.

Las ilustraciones del ilustrador catalán Carles Ballesteros, radicado en Chile, dan un aire de modernidad al libro, a la vez que acercan el cuento a la estética contemporánea.

\section{LA CENICIENTA}

Gran lectora de la literatura infantil clásica, Gabriela Mistral respetó siempre la versión original de los cuentos al crear sus propias versiones. En este sentido, no cambió ni dulcificó los finales como en muchas versiones de los hermanos Grimm, ni infantilizó los textos que no recarga de diminutivos ni onomatopeyas como suele hacerse erróneamente cuando se escribe para los niños a quienes la autora no subestima. Escribió para ellos con un lenguaje lleno de matices y expresiones literarias muy ricas, lo que hace que estas versiones sean apreciadas tanto por el niño como por el adulto.

En el caso de esta versión, vemos que la autora se ciñó al cuento de Charles Perrault pues la escena del baile se cuenta dos veces, en cambio en la versión de los hermanos Grimm aparece reducida a una sola. Este recurso del desdoblamiento fue muy utilizado en la estética barroca del siglo XVII, cuando se tendía a recargar la obra artística empleando el juego de espejos para multiplicar la realidad, creando juegos ópticos, tal como en el cuadro "Las Meninas" de Velázquez en el que el propio pintor se introduce en el cuadro que está pintando y a la vez, los reyes aparecen reflejados en un espejo que está al fondo de la estancia real. En 


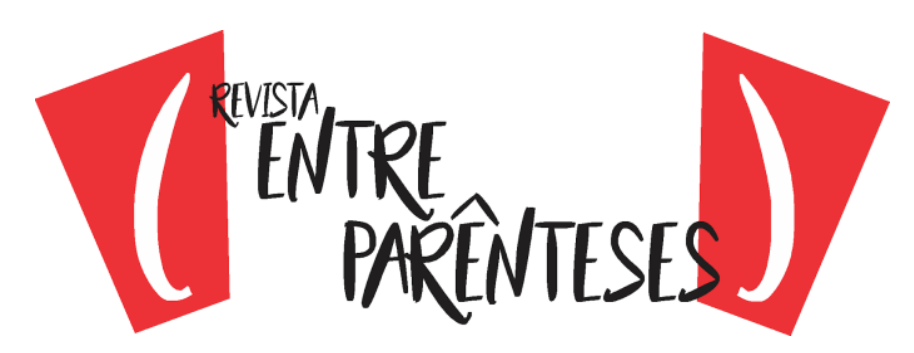

esta versión, la autora narra dos veces el baile, es decir, aparece repetido, con lo cual se apega a la raíz barroca del cuento y a su estética.

Como en los relatos de este tiempo, hay "brocados rojos", una calabaza convertida en carruaje de "concha perla" y tocadores que "hieren / misterios de cobre y plata". Atención con esta dupla de metales: "cobre y plata". Lo usual habría sido "oro y plata" pero la autora reemplaza el oro por el cobre que es metal asociado a la minería chilena, con lo cual, el cuento adquiere un tono americano. Así también en el baile hay una orquesta "de cobres", en circunstancias que hablamos "de bronces" para referirnos a los instrumentos de viento. Aquí el baile barroco va adquiriendo un tono mestizo, entre europeo y latinoamericano.

La autora tiene conocimiento de las civilizaciones antiguas. El hollín va cubriendo a la Cenicienta "como penitente saya" con lo cual asocia la imagen a la túnica que utilizaban los penitentes en las procesiones de Semana Santa. En esta comparación aparece reflejado su pensamiento cristiano, es decir, tal como ocurre en las expresiones del Modernismo literario, hay referencias bíblicas mezcladas al mundo pagano y mágico de los cuentos de hadas.

Su pensamiento cristiano coincide con el de Hans Christian Andersen al valorar al desposeído y al humilde. "El que se humilla será ensalzado". La ternura y el amor están puestos no solo en "la Encenizada", sino también en "los criados", en las "ratitas blancas" y en "los lagartos azules" que se hicieron "dos lacayos fulgurantes". En este verso introduce estos reptiles que deslumbraron a los conquistadores españoles por no haberlos en el continente europeo, con lo cual americaniza otra vez el cuento.

La autora en sus poemas siempre sintió piedad por los humildes a quienes defendió. No por azar se sintió atraída por esta Cenicienta desposeída. Es la Cenicienta misma, un personaje mistraliano, del mismo modo que se sintió conmovida por esos "piececitos de niño / azulosos de frío". 


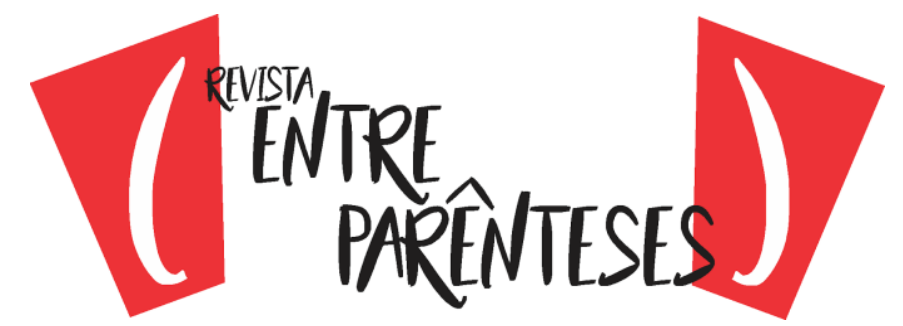

Un léxico muy rico y exótico nos sorprende. Cuando la Cenicienta entra al baile "se paran las guzlas". ¿Qué quiere decir? La autora nos obliga a ir al diccionario a buscar sus palabras enigmáticas que anotaba en un cuaderno y que luego empleaba en sus poemas para intrigarnos. Las guzlas son instrumentos musicales de una sola cuerda con la que los antiguos acompañaban sus poesías recitadas, con lo cual nos está diciendo que en ese baile de palacio había declamación de poesía acompañada con música. Nos ha abierto un mundo enriqueciendo el cuento con este detalle que pasaríamos por alto si no analizamos su complejo vocabulario.

Sorprendentes también son las comparaciones: la Cenicienta "baila como un pez". A la medianoche, "sube al carruaje que / como jabalina escapa". ¿Corre tan rápido como una jabalina en el aire? No. La jabalina es la hembra del jabalí que huye en el bosque a toda velocidad antes de ser sorprendida, del mismo modo que la Cenicienta huye del palacio, cuando el reloj da las doce campanadas, temiendo que su hermoso traje se convierta otra vez en "penitente saya".

Estos detalles mistralianos hacen que el cuento nos obligue a interpretarlo más profundamente, aunque conozcamos superficialmente la anécdota que la autora recrea. Del mismo modo, nos señala que salieron "cuarenta heraldos I voceando pregón de su majestad". ¿Por qué cuarenta? Nuevamente la autora emplea un recurso literario propio del Modernismo al fundir el mundo mágico de los cuentos de hadas con la tradición judeo cristiana, ya que el cuarenta es un número significativo en la cultura islámica. Cuarenta son los ladrones de Alí Babá, así como cuarenta fueron los días en que flotó el arca de Noé, cuarenta fueron los días que Moisés pasó en el monte Sinaí aguardando los diez mandamientos y cuarenta fueron también los días que Jesús ayunó en el desierto, de los cuales deriva el periodo de cuarenta días que preceden a la Semana Santa, llamado Cuaresma.

Profunda lectora de la Biblia desde su infancia en el valle del Elqui, la autora menciona que fueron cuarenta los heraldos que salieron a anunciar el pregón 


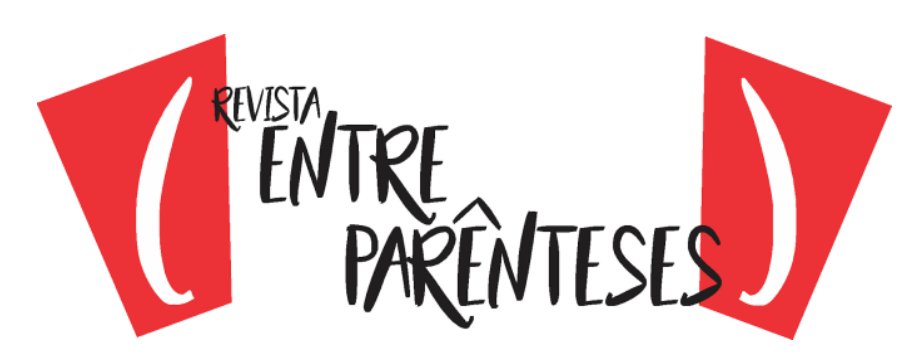

del príncipe pidiendo que se presentaran todas las muchachas casaderas a probarse el zapatito de cristal "más menudo que la ampolla de la sal". En este verso, la autora utiliza nuevamente la figura literaria de la hipérbole, al exagerar la pequeñez de un zapatito como un salero. Esto es pura originalidad mistraliana, del mismo modo que la Cenicienta calza finalmente "su piececito de almendra". El cuento clásico que conocemos se enriquece así con muchos matices literarios finísimos que pueden pasar inadvertidos si no leemos con atención.

Este libro está ilustrado por Bernardita Ojeda que hace uso de una gama de colores brillantes interpretando con acierto varios detalles literarios de la versión mistraliana.

\section{LA BELLA DURMIENTE DEL BOSQUE}

En sus versiones poéticas de los cuentos infantiles clásicos, la autora adopta el verso octosílabo que se aproxima muy bien al tono oral de la décima campesina tan cultivada en los campos de Chile. Desde su inicio, su versión de "La Bella Durmiente del Bosque" tiene el tono del relato oral contado al calor del brasero: "Hace tantos, tantos años / que imposible es el contar". Ya en los años 20, ella valoraba la oralidad que hoy día está otra vez en boga con el auge de los cuenta cuentos en toda Iberoamérica.

El recurso de la repetición, tan frecuente en la narrativa folclórica, está presente a lo largo de esta versión. Así escribirá: "Era linda, linda / como si no fuese verdad" y hablando de los husos del reino, dirá que "recogieron tantos, tantos, / que una parva se vio alzar". Muy significativo que asocie la montaña de husos con "una parva" de trigo, con lo que refleja su formación campesina. Del mismo modo, las hadas llegan al bautizo cargando un "morral" como los labradores lo llevan a la espalda con la merienda del día. También las hadas reparten el Bien y el Mal "como harina", evocando las faenas rurales de su amado valle del Elqui. 




Apegada al Modernismo literario, admira a Rubén Darío y José Martí, creadores de este movimiento estético que rescata la magia de los cuentos de hadas y el preciosismo de la palabra escrita. El poeta nicaragüense escribirá su poema cuento "A Margarita" del mismo modo que el poeta cubano escribirá "Los zapaticos de rosa", ambos delicados cuentos en verso. Inspirada en ellos, la autora escribirá estas versiones de cuatro cuentos clásicos. Pero no solamente es la forma del cuento de hadas versificado el que emulará del Modernismo, sino también la belleza y el refinamiento tan preciados en este movimiento literario. Así, en la mesa del bautizo habrá "un cubierto de oro puro / con diamantes de cegar", tal como en el poema "A Margarita" Rubén Darío describirá "un palacio de diamantes / una tienda hecha del día / y un rebaño de elefantes".

También hará aparecer aves exóticas, como un "faisán" y un "pavo real" con una cola en la que relucen un "millón de ojos ardientes", tal como Rubén Darío escribirá en su "Sonatina": "El jardín puebla el triunfo de sus pavos reales". Asimismo se refleja esta preocupación por la belleza de los cuentos maravillosos al describir a "cien doncellas" que seguían a la princesa "cual saetas en el aire de cristal". Y hasta la rica musicalidad del verso octosílabo recrea la estética sonora del verso modernista. Así, la paz está derramada en la princesa dormida cuyo párpado se cierra "puro sueño y suavidad" evocando la dulzura y delicadeza en la fonética del verso que utiliza consonantes suaves como la "s" y la " $\mathrm{v}$ " en las palabras como "sueño" y "suavidad".

También le interesa el exotismo de los instrumentos musicales. En este caso, "los cien músicos" interpretan una orquesta en la que se incluyen "las arpas y el timbal". Cuando la princesa se pincha el dedo, se duerme toda la corte: "el jardín intacto", "la fuente y el faisán" y hasta "se durmió la que lo cuenta" incluyéndose ella misma en el relato que está contando. Ella también se duerme mientras narra el cuento, es decir, la contadora se introduce en el mundo narrado, como el pintor 


\section{("ingme}

Diego Velázquez se incluye en el cuadro "Las Meninas" en una técnica propia de la estética barroca.

Vuelve a emplear la repetición al describir el bosque "negro, negro". Avanza el príncipe en ese bosque enmarañado que "esquivó Caperucita /santiguándose de horror...". En este par de versos, la autora hace aparecer a un personaje que proviene de otro cuento, en una proeza literaria inaudita. Estamos en plenos años 20 del pasado siglo, con lo cual se adelanta a su tiempo al introducir un recurso literario transgresor que rompe la linealidad del relato clásico. Esto es pura intertextualidad.

Muy original es la descripción del despertar de la Bella Durmiente cuyos labios "desabrochan". Aquí hay cierta ironía al preguntar: "- ¿Por qué tanto te tardaste/ oh, mi príncipe en llegar?". Como Charles Perrault, la autora pareciera que se sonríe al escribir estos versos porque ella también está jugando al escribir.

Emplea un arcaísmo al mencionar "la marmita" que además "comienza a gluglutear" con lo cual introduce un neologismo asociado a la onomatopeya de la olla al hervir. Hacia el final hay un gran crescendo en el que se describen todos los sucesos mágicos asociados al despertar de la bella durmiente para culminar con ese largo sueño transformado en "cien años" de amor.

El príncipe la mira temeroso de perderla si se vuelve a dormir pues "se puede disipar" tal como la autora escribirá en su poema "Hallazgo", al encontrar a un niño dormido "cuando al campo iba", experimentando el mismo sentimiento de temor a la pérdida. Así dirá en el poema: "y por eso temo, al quedar dormida / se evapore como la helada en las viñas", tal como el príncipe teme que la bella durmiente se pueda "disipar" si vuelve a dormirse. Por esta fusión entre sueño y realidad, este es uno de los cuentos más cercanos al mundo mistraliano.

Las ilustraciones de este libro pertenecen a la ilustradora Carmen Cardemil quien ha empleado diversas técnicas de las artes plásticas, entre ellas la acuarela, la témpera y el collage. 




\section{CONCLUSIÓN}

La aparición editorial de estos cuatro cuentos viene a complementar la obra de una autora que manejó al mismo tiempo la poesía, la prosa y el género epistolar con dominio y sensibilidad. Gabriela Mistral sostuvo una nutrida correspondencia con casi todos los escritores de su tiempo. Fue una gran escritora de cartas que escribía a mano untando su lapicera en tinta o en máquina de escribir. Cultivó el ensayo político, el recado, el artículo de costumbres, la descripción poética, el cuento, la ronda, la canción de cuna, la reseña literaria y el soneto clásico. Escribió sobre el americanismo, se interesó por la botánica y la fauna vernáculas. Estudió nuestras piedras, nubes, flores e insectos. Hasta el cardo más humilde atrajo su atención. Inspirada en Hans Christian Andersen a quien le dedicó un poema, se preocupó por los débiles y por la niñez desvalida. Escribió páginas notables sobre la maternidad, el papel educativo de las bibliotecas y el fomento de la lectura. Reflexionó sobre el cristianismo y reivindicó a los pueblos originarios. Fue una de las escritoras más completas de nuestra América en la variedad de sus temas y en la riqueza de su pensamiento.

Estos cuentos infantiles clásicos versionados por Gabriela Mistral enriquecen su obra literaria, especialmente la dedicada a la infancia. Es una suerte que la editorial Amanuta de Santiago de Chile los haya "despertado" después de casi "cien años" de ser escritos, lo que constituye un verdadero acontecimiento literario que recibimos con alegría.

\section{PREMIOS}

Esta colección de cuatro libros tuvo destacados premios tanto nacionales como extranjeros, entre ellos: 




- Premio a la edición del Premio Municipal de Literatura 2013 que la Municipalidad de Santiago organiza desde 1934;

- Premio The Best Designed Book of the year (El libro mejor diseñado del mundo) concedido en el año 2014 por la Comisión Alemana para la UNESCO junto con la German Book Art Foundation;

- "Caperucita Roja" ilustrado por Paloma Valdivia obtuvo la distinción White Ravens 2013 (Mirlos Blancos) que concede la Internationale Jugendbibliothek de Múnich (Biblioteca Internacional de la Juventud de Múnich);

- Mención Acierto Editorial Categoría Infantil, Banco del Libro, Venezuela, 2014;

- Mención Los Imprescindibles de la Biblioteca, Banco del Libro, Venezuela, 2014;

- La serie fue reconocida con una Mención de Honor en el premio New Horizons (Nuevos Horizontes) en la Feria del Libro Infantil de Bolonia 2014. (Bolonia Children's Book Fair). 




\section{Referências}

MISTRAL, Gabriela. El Folklore de los Niños, Revista de Pedagogía, Madrid, 1936. Gabriela anda por el mundo. Compilación de Roque Esteban Scarpa. Editorial Andrés Bello. Santiago, 1978.

Magisterio y niño. Compilación de Roque Esteban Scarpa. Editorial Andrés Bello. Santiago, 1979.

- Croquis mexicanos. Compilación de Alfonso Calderón. Editorial Nascimento. Santiago, 1979.

Poesía y prosa. Selección, prólogo, cronología y bibliografía de Jaime Quezada. Biblioteca Ayacucho. Caracas, Venezuela, 1993. Impreso en Chile.

MORALES BENÍTEZ, Otto. Gabriela Mistral: Su prosa y poesía en Colombia. Edición del Convenio Andrés Bello. Bogotá, 2002.

Recebido em: 06/06/2020

Aceito em: 10/06/2020 